\title{
Emerging subspecialties in neurology: Pain medicine
}

\author{
Irfan Lalani, MD
}

Traditionally neurologists have been considered masterful diagnosticians. Fellow physicians often rely on neurologists to sort out complex historical and examination data in order to arrive at a diagnosis and plan of action. Our specialty is also known for its expertise in the continuing longitudinal care of patients with serious illnesses that impact social and occupational function. Several neurologic diseases result in chronic pain, e.g., stroke, multiple sclerosis, and radiculopathy. For these reasons, neurologists are well suited to the practice of pain medicine.

One of the first US neurologists to contribute to pain medicine was Silas Weir Mitchell. In Injuries of Nerves and Their Consequences, he gave detailed case descriptions of causalgia (complex regional pain syndrome) and phantom limb pain. Subsequently, the concept of multidisciplinary pain management was pioneered by John Bonica, who founded the first interdisciplinary pain clinic in 1947 at Tacoma General Hospital. Currently, the practice of pain medicine involves physicians from multiple specialties including physiatry, psychiatry, anesthesiology, neurosurgery, and neurology.

In a survey of practicing US neurologists, $77.4 \%$ of respondents reported that they manage patients with chronic headache, whereas $47.6 \%$ cared for patients with chronic spine and limb pain. ${ }^{1}$ Other painful conditions that are seen by neurologists include neuropathy, failed back syndromes, radiculopathy, and postherpetic neuralgia..$^{2,3}$ Neuropathic pain syndromes affect more than 3 million Americans ${ }^{4}$ and migraine headaches affect $15 \%$ of the US population. ${ }^{5}$ Despite the large number of patients who neurologists see with pain-related complaints, data suggest that there is considerable room for improvement in pain-related training during residency and beyond.

Galer et al. conducted a survey of practicing neurologists and neurology program directors. Thirty percent of respondents reported that they were adequately trained to diagnose pain-related disorders; only $20 \%$ felt adequately trained to treat these conditions. A large majority (89\%) stated the need for more painrelated training during residency and $91 \%$ wanted more pain education for practicing neurologists. Interestingly, neurology program directors rated pain medicine seventh in importance of eight neurology subspecialties. Only $29 \%$ of neurology programs had a pain specialist on faculty and $5 \%$ had a mandatory pain clinic rotation, reflecting a current paucity of pain education in neurology residency programs. ${ }^{6}$ As a first step to rectify this situation, the American Academy of Neurology published a pain medicine core curriculum for neurology residents in 2001 (http://www.aan. com/about/sections/residency/pain. pdf). This document clearly documents educational objectives for residents based on their level of training.

Pain medicine was recognized in 1998 by the American Board of Medical Specialties (ABMS) as a neurologic subspecialty. The first pain medicine certification examination was given by the American Board of Psychiatry and Neurology $(\mathrm{ABPN})$ in 2000. There are currently four approved pain medicine fellowship programs listed on the Accreditation Council on Graduate Medical Education (ACGME) Web site (www.acgme. org), while 18 neurologists were certified in pain medicine in 2005 (www.abpn.org). Other specialties with accredited pain medicine fellowships include anesthesiology (90 programs), physical medicine and rehabilitation (11 programs), and psychiatry (1 program). The ACGME has uniform accreditation criteria for all pain fellow-

See also pages 1333, 1521, 1524-1525

Disclosure: The authors report no conflicts of interest.

Address correspondence and reprint requests to Dr. Irfan Lalani, Department of Anesthesiology, Section of Pain Management, MD Anderson Cancer Center, Houston, TX, 77030; e-mail: irfan.lalani@gmail.com

1522 Copyright () 2006 by AAN Enterprises, Inc. 
ships. These include training in interventional procedures, behavioral and psychological approaches, pharmacotherapy, and rehabilitation. Several non-neurology based pain fellowships also accept neurology applicants but there remains a need for expanding access for neurologists to multidisciplinary pain fellowships.

Fellowship training in pain management involves the development of skills required to diagnose and treat acute, chronic non-malignant, and cancerrelated pain. Expertise is developed in the use of pharmacologic agents including antidepressants, antiepileptic agents, and opioids. The appropriate use and performance of fluoroscopic guided procedures, e.g., zygapophysial joint blocks, selective nerve root blocks, and spinal cord stimulation, should be mastered during pain fellowship training. Training should also integrate behavioral approaches to pain including psychological evaluation and treatment of psychiatric comorbidities. Physical therapy and rehabilitation represent an important adjunct to multidisciplinary pain management. Completion of a comprehensive pain fellowship prepares the neurologist to provide evidence-based, multimodality effective patient care.

There are a variety of career options open to the neurology pain specialist. These include academic practice, private practice, and pharmaceutical/device manufacturing industry. An abundance of research opportunities exist in this nascent field. These include investigating basic molecular mechanisms of pain transduction, functional neuroimaging to evaluate changes in cerebral function related to chronic pain, and outcomes-based research to identify optimal pharmacologic and interventional therapies for acute and chronic pain. The deficiencies in pain-related education and the scarcity of faculty pain specialists will also result in an increased demand for academic pain specialist faculty.

Conventional randomized controlled trials may not be the best tool for assessing chronic pain therapies. ${ }^{7}$ Neurologists have been involved in innovative trial designs that better assess the chronic as well as episodic nature of some painful conditions including migraine. ${ }^{8}$ Neurology pain specialists may therefore become involved with academic pain trial groups and industry and contribute to the development of novel therapeutic strategies for chronic pain.

Private practice affords the ability to develop physician-patient relationships based on continuity of care. Greater physician autonomy allows for selecting patients according to subspecialty interest and expertise. Other advantages include higher income potential and greater opportunities to develop an interventional-multidisciplinary pain practice.

There are a large number of patients with chronic pain condi- tions. A tremendous need exists to provide these patients with effective care and reduce their painrelated suffering and disability. The neurology pain specialist has a vital role in this regard. Painrelated education should be emphasized during neurology residency as well as for practicing neurologists. Further work remains to be done to encourage neurologists to specialize in pain medicine.

\section{Acknowledgment}

The author thanks Drs. Jerome Kurent, Charles Argoff, Everton Edmondson, and Misha Backonja for their help with this article.

\section{References}

1. American Academy of Neurology Practice Characteristics Subcommittee. Neurologists 2000. St Paul, MN: American Academy of Neurology, 2001;18.

2. American Academy of Neurology Ethics, Law and Humanities Committee. Ethical considerations for neurologists in the management of chronic pain. Neurology 2001;57: 2166-2167.

3. Jacobson PL, Mann J, Douglas MD. Evolving role of the neurologist in the diagnosis and treatment of chronic noncancer pain. Mayo Clin Proc 2003;78:80-84.

4. Irving GA. Contemporary assessment and management of neuropathic pain. Neurology 2005;64:S21-27.

5. Bigal ME, Liberman JN, Lipton RB. Agedependent prevalence and clinical features of migraine. Neurology 2006;67:246-251.

6. Galer Bradley, Keran C, Frisinger M. Pain medicine education among American neurologists: A need for improvement. Neurology 1999;52:1710-1712.

7. Max Mitchell B. Five steps to increase the payoff of chronic pain trials. Neurology 2005 65:S74-S77.

8. Lipton RB, Bigal ME, Stewart WF. Clinical trials of acute treatments for migraine including multiple attack studies of pain, disability, and health-related quality of life. Neurology 2005;65:S50-S58. 


\title{
Neurology
}

\author{
Emerging subspecialties in neurology: Pain medicine \\ Irfan Lalani \\ Neurology 2006;67;1522-1523 \\ DOI 10.1212/01.wnl.0000243249.95381.b7
}

This information is current as of October 23, 2006

Updated Information \& Services

References

Citations

Permissions \& Licensing

Reprints including high resolution figures, can be found at: http://n.neurology.org/content/67/8/1522.1.full

This article cites 7 articles, 6 of which you can access for free at: http://n.neurology.org/content/67/8/1522.1.full\#ref-list-1

This article has been cited by 2 HighWire-hosted articles: http://n.neurology.org/content/67/8/1522.1.full\#\#otherarticles

Information about reproducing this article in parts (figures,tables) or in its entirety can be found online at:

http://www.neurology.org/about/about_the_journal\#permissions

Information about ordering reprints can be found online:

http://n.neurology.org/subscribers/advertise

Neurology ${ }^{\circledR}$ is the official journal of the American Academy of Neurology. Published continuously since 1951, it is now a weekly with 48 issues per year. Copyright . All rights reserved. Print ISSN: 0028-3878. Online ISSN: 1526-632X.

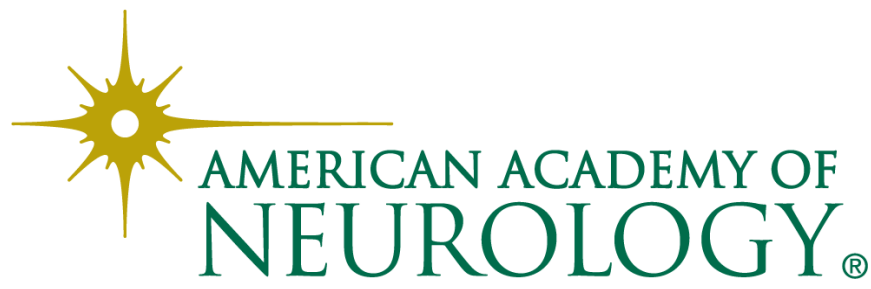

